\title{
There is no neutral aspect ${ }^{*}$
}

\author{
Daniel Altshuler \\ Heinrich-Heine-Universität Düsseldorf
}

\begin{abstract}
This paper considers the Hindi $-y a a$ and the Russian $-y v a$, which share many properties that are characteristic of so-called neutral aspect-an aspect whose meaning generalizes across the perfective and imperfective. Proponents of neutral aspect assume that (im)perfectivity is defined in terms of reference to an event's completion. This paper refines this idea, distinguishing between an event that culminated and one that ceased to develop further. The latter notion comes from Landman's (1992) analysis of the progressive, which denotes a function from a set of events in the extension of the VP that it combines with to a set of event stages that develop into VP-events according to a particular recipe. Building on Landman's analysis, I propose that a perfective operator is one that requires a maximal stage of a VP-event; an imperfective operator is one that requires a VP-event stage, but this stage need not be maximal. I show how this analysis allows us to analyze the Hindi $-y a a$ and the Russian $-y v a$ as being perfective and imperfective respectively, without any reference to neutrality.
\end{abstract}

Keywords: aspect, perfective, imperfective, neutral

\section{Introduction}

Neutral aspect is a term that was introduced by Carlota Smith (Smith 1994) to describe aspectual forms that appear to have semantic characteristics of both the perfective and imperfective aspect. In a recent typological survey, Dahl (2010) writes: “...there is evidence that the neutral aspect can be shown to represent an

\footnotetext{
* Thanks to María J. Arche, Ashwini Deo, Hana Filip, Fabienne Martin and Roger Schwarzschild for discussions that lead to many substantial improvements. Thanks to the participants at the following venues, where related work was presented: Workshop on modality at ICL 19, SALT 23, Workshop on Slavic Aspect at Bar Ilan University, Workshop on Aspect at CHRONOS 10, Utrecht-Leiden Semantics Happenings, The Rutgers Semantics Research Group, Semantics Group at Cornell, and Semantics Tea at UCLA. Thanks also to the participants in my seminars on aspect (co-taught with Hana Filip) at Heinrich Heine Universität and the participants and consultants in my fieldwork methods class on Hindi at Swarthmore. Last but certainly not least, thanks to Rajesh Bhatt and Aparajita Bhattacharyaa for answering my frequent emails and many others who helped with the data (too many to list; you know who you are!). The usual disclaimers apply.
}

(C)2013 Daniel Altshuler 
aspectual type which behaves differently than the imperfective, the perfective and the anterior aspect" (ibid: 88). The key evidence that Dahl draws on is the observation that past neutral forms of telic verbs are compatible with both a "processual" and a "completive" reading. This, according to Dahl:

(1) ...indicates that the neutral aspect is distinct from the perfective a well as from the imperfective aspect. Specifically, perfective forms of telic predicates are generally incompatible with progressive-processual interpretation, whereas corresponding imperfective forms tend to be incompatible with a completive-sequential reading... (ibid: 88-89)

As an example of what Dahl had in mind, consider the Russian -yva in (2) and (3) below. It can be used to describe: (i) a change of state between a window being closed and it being open, i.e. a "completive" reading, and (ii) an ongoing process of Columbus discovering America, i.e. a "processual" reading.

Da, ja otkr-yva-l okno.

Yes, I open-yva-PST window

'Yes, I \{have opened/did open\} the window.'

$$
\begin{aligned}
& \text { O, bud'te uvereny, čto Kolumb by-1 sčastliv ne togda, kogda } \\
& \mathrm{O} \text { rest assured that Columbus be-PST happy not then when } \\
& \text { otkry-1 Ameriku, a kogda otkr-yva-l ee. } \\
& \text { open-PST America but when open-yva-PST it }
\end{aligned}
$$

'Oh, rest assured that Columbus was happy not when he discovered America, but while he was discovering it.' (Dostoevskij, Idiot; quoted by Vinogradov 1972 and cited in Rassudova 1984: 15)

$-y a a$ in Hindi can also be used to describe a change of state. (4) illustrates that this inference can be canceled to describe a processual cookie-eating event.

$$
\begin{aligned}
& \text { maayaa-ne biskuT-ko khaa-yaa (par use puuraa nahiin khaa-yaa) } \\
& \text { Maya-ERG cookie-ACC eat-yaa but it-ACC finish not eat-yaa } \\
& \text { 'Maya ate the cookie (but did not finish it).' (Singh 1991, 1998) }
\end{aligned}
$$

The cancellation in (4) is in accordance with Pancheva's (2003) generalization that the use of neutral aspect leads to an implicature that the described event was completed, never an entailment. This generalization not only applies to Hindi $-y a a$ but to the Russian $-y v a$ as well (Leinonen 1982):

$$
\begin{aligned}
& \text { Ja dočit-yva-I poslednie stročki pis'ma (xotja ne do konca). } \\
& \text { I read.up-yva-PST last lines letter even.though not until end } \\
& \text { 'I read the last lines of the letter (though not until the end).' }
\end{aligned}
$$


Interestingly, Pancheva's generalization does not seem to apply to achievements. Smith (1994) observes that neutral aspect of achievements leads to the entailment that the described event was completed. This generalization was independently made by Singh $(1991,1998)$ about Hindi. For example, consider (6) below, where $-y e$ (a phonological variant of $-y a a$ ) leads to the entailment that the father crossed the threshold of the speaker's house. We know this to be the case because the follow-up that attempts to cancel this inference is infelicitous.

pitaa-jii hamaare ghar aa-ye (\#lekin hamaaraa ghar nahiiN DhuunD sake) father our house come-ye but our house not find could 'Father came to our house (\#but was unable to find it).' (Rajesh Bahtt, pc.)

Based on such examples, Singh concluded that $-y a a$ (and its phonological variants) combines with achievement verbs to "indicate that the described action was completed" (ibid: 183). Similarly, as discussed in the next section, Russian achievement VPs whose aspectual profile is identical to those with $-y v a$ lead to the entailment that the described event was completed. This raises the question of why particular forms in genetically unrelated languages lead to two distinct interpretations (completive and processual), and one of these interpretations (completive) constitutes an entailment when achievement VPs are used.

As noted at the outset, one answer to the question is to say that - in addition to the traditional three-way distinction between the perfective, the imperfective and the perfect - there is an aspectual class called neutral aspect. It has a meaning that generalizes across (at least) the perfective and the imperfective and, for whatever reason, is sensitive to the distinction between achievements and nonachievements. Some version of this idea has played a vital role in many analyses of aspect. ${ }^{1}$ Of course, it presupposes a particular analysis of (im)perfectivity, e.g. the classical view advanced by Comrie (1976) and outlined by Dahl in (1) above. But why should we assume that (im)perfectivity is what (1) says it is?

An important cross-linguistic fact that leads us to reconsider (1) is that in language after language, the truth conditions of forms that have traditionally been called perfective do not appear to lead to a completive interpretation. ${ }^{2}$ Notions like non-completive perfective and semi-perfective have subsequently been introduced in addition to neutral perfective (see e.g. ter Meulen 1995, Koenig \&

\footnotetext{
${ }^{1}$ See, e.g. Schilder 1995, Iatridou et al. 2001, Giorgi \& Pianesi 2001, Pancheva 2003, Deo 2006: 104, Boneh \& Doron 2008, Dahl 2010: §1.2, Travis 2010; see Csirmaz 2004 for more discussion.

${ }^{2}$ Here is a sample of languages for which this claim has been made: SENĆOFEN (Kiyota 2008); Japanese (Ikegami 1985); Karachay-Balkar (Tatevosov 2008); Malagasy (Travis 2000); Mandarin (Teng 1972, Koenig \& Chief 2008); Punjabi (Raja 2003); St'át'imcets and Skwxwúmesh (Bar-el Davis \& Matthewson 2005); Tagalog (Dell 1987); Tamil (Pederson 2007); Thai (Koenig \& Muansuwan 2000), among many others.
} 
There is no neutral aspect

Muansuwan 2000). In fact, the Hindi $-y a a$ discussed above is a suffix that every Hindi grammarian calls perfective, and yet, given the position in (1), we are forced to see it as a special kind of a perfective, perhaps not a perfective at all. Moreover, the Russian -yva discussed above is a suffix that every Russian grammarian calls imperfective, and yet given the position in (1), some have concluded that "...there is no such thing as the meaning of the imperfective; this 'aspect' is really a non-aspect" (Paslawska \& von Stechow 2003: 336).

This paper argues that we can treat the Hindi $-y a a$ as a perfective suffix and the Russian $-y v a$ as an imperfective suffix, without any reference to neutrality, if we refine the notion of completion mentioned in (1). In particular, I would like to distinguish between: an event that culminated and an event that ceased to develop further. This distinction is perhaps clearest when thinking about an event like running a marathon. If one crosses the finish line, then the event culminates, thereby verifying the description ran the marathon. If the runner continued to run beyond the finish line, it would not be the same kind of event as the one described by ran the marathon. If, on the other hand, one stops in the middle of the race, then the description ran the marathon would not be verified. The event of running would cease to develop into the kind of event described by ran the marathon.

The notion of an event's development is borrowed from Landman's (1992) analysis of the English progressive, according to which this aspect denotes a function from a set of events in the extension of the VP that it combines with to a set of event stages that develop into VP-events according to a particular recipe. In the next two sections, I motivate an analysis in which both perfective and imperfective operators denote functions which return VP-event stages. Both could describe an event's culmination; this depends, in part, on whether the operator requires proper event stages in the extension of the VP that it combines with. In other words, the combination of an aspectual operator with a VP could (but need not) result in a telic predicate, but this is independent of (im)perfectivity (cf. Borik 2006). Subsequently, I build on insight from Koenig \& Muansuwan (2000) and Filip $(2000,2008)$ and propose that perfective operators differ from imperfective ones in that only the former impose a maximal stage requirement, which is satisfied when a VP-event culminates or ceases to develop in the actual world. An important consequence of this analysis is that it allows us to dispense with the notion of 'neutral aspect' since we now have a clear way of differentiating between imperfective and perfective operators:

(7) Hypothesis about (im)perfective operators

a. An operator is perfective if it requires a maximal stage of an event in the extension of the VP that it combines with.

b. An operator is imperfective if it requires a stage of an event in the extension of the VP that it combines with, but this stage need not be maximal. 


\section{Semantic constraints imposed by the Russian imperfective}

This section motivates and accounts for the hypothesis that there is a correlation between grammatical aspect and VP meaning in Russian. The hypothesis is driven by inferences about an event's culmination. I only consider sentences with telic VPs since, by definition, only telic VPs describe culminations (Parsons 1990).

\subsection{A note on Russian aspectual morphology}

According to the Russian Academy Grammar (1960), every verbal form in Russian is either perfective or imperfective. Imperfective verbal stems can be morphologically simple or complex. In the former case, they provide a basis for the derivation of the perfective forms, which arguably involves prefixation. ${ }^{3}$ The examples below, in (8), illustrate that the aforementioned suffix $-y v a$ (and its phonological variants) can be added to a complex perfective verb, which in turn is derived from a simple imperfective verb. This process is often referred to in the literature as secondary imperfectivization.
a. pisat write.IPF
za-pisat'
za-pis-yva-t'
'to write'
[PFV-[write.IPF]]
[[PFV-[write.IPF] $]-I P F]$
b. govorit'
tell.IPF
'to write down'
'to write/be writing down'
'to tell'
po-govorit'
[PFV-[tell.IPF]]
'to talk for a bit'
c. bolet'
za-bolet'
po-govar-iva- $t^{\prime}$
[[PFV-[tell.IPF]]-IPF]
'to talk/be talking for a bit'
be.ill.IPF
[PFV-[be.ill.IPF]]
'to be ill'
'to become ill'
d. znat'
u-znat'
za-bol-eva-t'
[[PFV-[be.ill.IPF]]-IPF]
'to become/be becoming ill'
know.IPF
'to know'
[PFV-[know.IPF]]
'to learn'
$u$-zn-ava-t'
[[PFV-[know.IPF]]-IPF]
'to learn/be learning'

It should be noted that according to Dahl's criteria discussed at the outset, no Russian form should ever be glossed imperfective; forms should glossed as being 'neutral' or 'perfective.' Since what's at stake here is whether Russian does, in fact, have the distinction glossed in (8), the examples in the introduction were not glossed for aspectual distinctions (e.g. -yva was simply glossed as '-yva'). From here on out, however, I will gloss every verb as perfective or imperfective and show how glossing the verbs in this way fits the definition of (im)perfectivity in (7). ${ }^{4}$ To avoid circularity, I will gloss the aspectual distinction according to an

\footnotetext{
${ }^{3}$ Cf. Arguments by Filip (2008) that perfectivity comes from a silent operator and that the prefixes have a semantic function independent of perfectivity.

${ }^{4}$ Note that I will not indicate the morphological derivations in the glosses, choosing to adopt the convention of simply marking the form as imperfective (IPF) or perfective (PFV).
} 
independently motivated diagnostic which is used by all Russian grammarians and teachers, and which I take to be the most reliable: imperfective verbs are possible with the auxiliary budet ('will'), while perfective ones are not. I refer the reader to Maslov 1984 for other diagnostics and Grönn 2003 for discussion.

\subsection{Culmination entailment hypothesis}

Let us begin by considering the Russian example in (9), where the imperfective sentence has the achievement VP, priezžal otec ('father arrived'). ${ }^{5}$ That this VP is an achievement can be shown by the observation that it cannot occur with the present tense to mean something like "is arriving", viz. (10) below; one would have to use the atelic VP edet ('going') instead (Kagan 2007a). In contrast, an imperfective accomplishment VP like dočityvat' poslednie stročki pis'ma ('to read up the last lines of the letter') can co-occur with the present tense viz. (11) below.

$\mathrm{K}$ nam priezža-l otec, no vskore u-exa-l.

To us arrive.IPF-PST father but in.a.rush PFV-go-PST

'Father had come to see us, but went away again soon.' (Rassudova 1968)

$$
\begin{aligned}
& \text { \#Smotri-vot priezža-et Sergej. } \\
& \text { Look there arrive.IPF-PRS Serge } \\
& \text { 'Look-Serge arrives.' (Stephen Dickey, p.c.) } \\
& \text { (11) Smotri-vot on dočit-yva-et poslednie stročki pis'ma. } \\
& \text { Look there he read.up-yva-PST last lines letter } \\
& \text { 'Look-he is reading up the last lines of the letter.' }
\end{aligned}
$$

The contrast above leads to the following generalization:

(12) If an imperfective VP is impossible with the present, it is an achievement.

Let us now return to the interpretation of (9). As noted by Rassudova, the father is understood to have arrived, before leaving shortly thereafter. It is not clear, however, whether it is the imperfective VP that leads to the understood culminated arrival; the sentence no vskore uexal ('but he left soon') makes it impossible to tell since one cannot leave a location if he did not arrive there first.

Evidence that priezžal ('arrived') leads to such a culmination entailment comes from the observation that if we replace no vskore uexal ('but he left soon') with no on ne smog najti naš dom ('but was unable to find our house') as in (13) below, the resulting sentence is odd. This contrasts with (14), where the

\footnotetext{
${ }^{5}$ Note that the VP in (9) is a derived, secondary imperfective. The reason that the suffix $-y v a$ is not apparent is that the derivation involves suppletion. See Townsend 1975 for more discussion.
} 
progressive does not lead to an entailment that arrival culminated and therefore it makes sense to assert that the father was unable to find the speaker's house.

(13) K nam priezža-l otec domoj, (\#no on ne smog najti naš dom). To us arrive.IPF-PST father home but he not able find our house 'Father came to see us at home, but was unable to find our house.'

(14) Father was coming to see us at home, but was unable to find our house.

Examples parallel to (13) could be constructed with other imperfective achievements, which always lead to a culmination entailment, e.g.:
a. doxodit' ('to reach by foot')
b. prixodit' ('to arrive by foot')
c. zaxodit' ('to come in by foot')
d. priletat' ('to arrive by plane')

Like priezžat', these forms are derived secondary imperfectives, i.e. they are derived from perfective forms. This leads us to the following hypothesis:

All Russian imperfective achievements are derived imperfectives.

These are the only forms that lead to a culmination entailment. As we saw at the outset, in (5), derived imperfective accomplishments do not lead to a culmination entailment. Therefore, I propose:

In Russian, a sentence with an imperfective VP entails that a described event culminated if and only if the imperfective VP is an achievement.

Given (16), we can rephrase (17) as follows:

(18) The Russian imperfective gives rise to an entailment that a described event culminated if it combines with a perfective VP describing a culmination. ${ }^{6}$

An important consequence of (18) is that we have evidence that underived, imperfective VPs in Russian never describe an event's culmination; only the perfective can telicize base VPs in Russian. While this position is held by most researchers working on Russian aspect, it is not easy to prove it. Zucchi (1999) calls this the problem of indirect access: how do we determine the semantics of base VPs? Suppose that they are predicates of events. Do they denote sets of complete events or not? Zucchi showed that the choice is important to how we approach the semantics of the English progressive, but, unfortunately, there is no conclusive evidence to choose one or the other. With respect to the Russian imperfective, however, Zucchi argues that we have morphological evidence. He considers the imperfective form pisat' ('to write'), which can combine with the prefix $n a$ - to yield the perfective napisat' ('to write up') and reasons: "if the

${ }^{6}$ As argued extensively by Borik (2006: 76-96), the perfective need not describe an event's culmination (e.g. Petja poiskal knigu 'Peter looked for a book (for a bit)'). 
perfective prefix $n a$ - is assumed to combine with predicates of complete events, then, in addition to the imperfective form pisat', we would have to posit a homophonous perfective form pisat' that never occurs unless it's combined with a perfective prefix." This would be a dubious analysis, and Zucchi concludes that base VPs in Russian denote a set of 'incomplete events.'

An underlying assumption in this argument is that base VPs in Russian are imperfective. However, why must this be the case? For example, the base VP pisat' could denote a set of complete events and this denotation could combine with either a silent imperfective operator to yield a set of incomplete events or a perfective operator to return a set of complete events. Such an analysis is certainly conceivable (see, e.g. Altshuler 2010, 2012) and it brings us back to the problem of indirect access. An important consequence of the data provided here is that it addresses the problem: base VPs in Russian do not denote a set of complete events because if they did, we would expect there to be culmination entailments with non-secondary imperfective forms, i.e. those that are not derived from the perfective. However, as we have seen, imperfective forms give rise to culmination entailment only when they are derived (achievements).

Let us now move on to reconsider the aforementioned sentence in (2) in light of the discussion above. Without further context, otkryval okno ('opened the window') describes the change of state from a window being closed to being open. However, the same VP need not interpreted as an achievement, as it can occur with the present tense (viz. Ja otkryvaju okno 'I am opening the window'). Similar observations can be made for a wide range of verbs:

a. otkryvat' okno ('to open the window')

b. zavozit' produkty ('drop off groceries')

c. darit' ej cvety ('give her flowers')

d. vyigryvat' matč ('win a match')

Relating these observations to the hypothesis in (17) above, we can say that the culmination inference with such VPs does not constitute an entailment because they are compatible with non-achievement interpretations. I come back to this point in the next section, where an analysis for the imperfective is proposed.

\subsection{Analysis of the culmination entailment with the Russian imperfective}

Landman (1992) proposes that sets of events can be ordered by a 'part-of' and a 'stage-of' relation. The latter is a special case of the former since "to be a stage, a part has to be big enough and share enough with [an event] e so that we can call it a less developed version of e" (Landman 1992: 23). Landman uses the stage-of relation to define the progressive operator: PROG denotes a function from a VP denotation, i.e. a set of events, to a set of VP-event stages. A progressive sentence 
is true if a VP-event stage develops into an event of the kind denoted by the VP in some possible world that is 'near enough' to the world of evaluation. ${ }^{7}$

Landman's idea is made more precise by the meaning of PROG below, in (20), which combines with a set of events $P$ and requires an event $e^{\prime}$ that is instantiated in the actual world $w^{*}$ to be a stage of a $P$-event $e$ in a 'near enough' world $w$. This requirement is encoded by the STAGE relation, whose semantics are spelled out in (20): $\operatorname{STAGE}\left(e^{\prime}, e, w^{*}, w, P\right)$ is true iff (i) the history of the world denoted by $w$ is the same as actual world up to and including the run time of the event denoted by $e^{\prime}$, (ii) the world denoted by $w$ is a reasonable option for the event denoted by $e^{\prime}$, (iii) $e$ has the property $P$ in $w$, and (iv) the event denoted by $e^{\prime}$ is a proper part of the event denoted by $e^{8}$

$$
\begin{aligned}
& \text { a. PROG } \rightsquigarrow \lambda P \lambda e^{\prime} \exists e \exists w\left[\operatorname{STAGE}\left(e^{\prime}, e, w^{*}, w, P\right)\right] \\
& \text { b. } \llbracket \operatorname{STAGE}\left(e^{\prime}, e, w^{*}, w, P\right) \rrbracket^{2 n,} \mathrm{~g}=1 \text { iff }(\mathrm{i})-(\mathrm{iv}) \text { holds: } \\
& \text { (i) the history of } \mathrm{g}(w) \text { is the same as the history of } \mathrm{g}\left(w^{*}\right) \\
& \text { up to and including } \tau\left(\mathrm{g}\left(e^{\prime}\right)\right) \\
& \text { (ii) } \mathrm{g}(w) \text { is a reasonable option for } \mathrm{g}\left(e^{\prime}\right) \text { in } \mathrm{g}\left(w^{*}\right) \\
& \text { (iii) } \llbracket P \rrbracket^{2 n,} \mathrm{~g}(e, w)=1 \\
& \text { (iv) } \mathrm{g}\left(\mathrm{e}^{\prime}\right) \sqsubset \mathrm{g}(\mathrm{e})
\end{aligned}
$$

Note that PROG does not relate an event to a topical time, as is commonly assumed in the literature on aspect (Kamp \& Rohrer 1983, Kamp \& Reyle 1993, Smith 1994, Klein 1994). ${ }^{9}$ This seeming oversight is for the sake of simplicityto abstract from issues about how tense and aspect interact. The operator in (20) therefore should be seen as a constraint on the meaning of the progressive.

Moreover, note that PROG is treated as an eventuality description modifier,

\footnotetext{
${ }^{7}$ This builds on Dowty's (1979) monumental analysis. See e.g. Bonomi 1997, Portner 1998, Condoravdi 2009 for other implementations, which are compatible with what is proposed here.

${ }^{8}$ Landman's meaning for PROG also involves a continuation branch function that allows one to trace how an event that is instantiated in the actual world develops in some possible world.

${ }^{9}$ There are two well-known approaches: (i) there is a 'progressive state' which contains the topical time (Moens \& Steedman 1988, Kamp \& Reyle 1993, Kamp et al 2011) and (ii) there is an event in the extension of the VP that contains the topical time (e.g. Klein 1994, Kratzer 1998). The problem with (i) is that it's unclear how the 'progressive state' is compositionally derived from an underlying event. The problem with (ii) is that the event in the extension of the VP is existentially quantified over and thus does not account for the imperfective paradox when the VP is an accomplishment. Those that subscribe to (ii) often acknowledge this shortcoming, implicitly assuming that the proposed meaning could be enriched with a modal semantics. In particular, the existential quantification is not really over a VP-event, but a VP-event-part. However, the question then becomes: what VP-event-part is related to the topical time and what is this relation like? Does the VP-event-part contain the topical time or is it the other way around?
} 
which maps a set of eventualities onto another set of eventualities. This is meant to: (i) allow the possibility of coercion operators to apply to the meaning of progressive VPs and return a set of coerced eventualities (cf. de Swart 1998; 2000; Bary 2009) and (ii) allow us to remain neutral about the syntactic distribution of PROG with respect to other aspectual operators, which I assume to also be eventuality description modifiers.

Finally, note that the condition in (20)iv is not what Landman proposes. He proposes that the event denoted by $e^{\prime}$ must be a part of the event denoted by $e$; it just need not be a proper part. In what follows, I'd like to show how maintaining the condition in (20)iv for PROG allows us to account for a key difference between the English progressive and the Russian imperfective (cf. Filip 1999). To that end, I propose that Russian has the partitive operator in (21), which is like (20) except that (21)iv has non-proper containment:

a. $\operatorname{IPF}_{\mathrm{RUSS}} \leadsto \lambda P \lambda e^{\prime} \exists e \exists w\left[\operatorname{STAGE}^{*}\left(e^{\prime}, e, w^{*}, w, P\right)\right]$

b. $\quad \llbracket \operatorname{STAGE}^{*}\left(e^{\prime}, e, w^{*}, w, P\right) \rrbracket^{2 n, \mathrm{~g}=1} 1$ iff (i)-(iv) holds:

(i) the history of $\mathrm{g}(w)$ is the same as the history of $\mathrm{g}\left(w^{*}\right)$ up to and including $\tau\left(\mathrm{g}\left(e^{\prime}\right)\right)$

(ii) $\mathrm{g}(w)$ is a reasonable option for $\mathrm{g}\left(e^{\prime}\right)$ in $\mathrm{g}\left(w^{*}\right)$

(iii) $\llbracket P \rrbracket^{2 n, g}(e, w)=1$

(iv) $\mathrm{g}\left(\mathrm{e}^{\prime}\right) \sqsubseteq \mathrm{g}(\mathrm{e})$

Applying (21) to the aforementioned (13), we would say IPF RUSS $_{\text {combines }}$ with the perfective VP priexat' ('arrive') and requires that there be an event $e^{\prime}$ in $w^{*}$ that is a stage of an event $e$ in the extension of priexat' in a 'near enough' world $w$. If we assume that priexat' denotes a set of atomic stages by virtue of being an achievement, then the requirement imposed by $\mathrm{IPF}_{\mathrm{RUSS}}$ is trivial. That is, given that an atomic stage is one that develops into itself in the world of evaluation (and presumably every other possible world), we expect (13) to entail that the father arrived at the location of the speaker. This is the desired prediction.

$\mathrm{IPF}_{\mathrm{RUSS}}$ applied to an accomplishment VP, however, does not lead to a culmination entailment assuming that accomplishment events have at last two

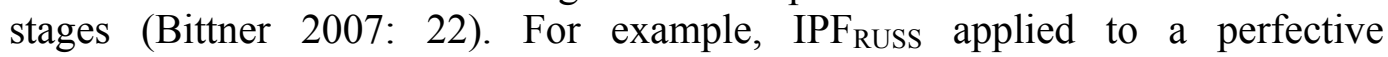
accomplishment such as dočital poslednie stročki pis'ma ('read up the last lines of the letter') in (5), correctly predicts this sentence to entail that a stage of a reading-up event culminated and crucially not that a reading-up event culminated.

The analysis also allows us to explain the difference between the Russian imperfective in (13) and the English progressive in (14), which has the following paraphrase: "there was an event going on which if not interrupted culminated in the speaker's father's arrival at the house". According to this paraphrase, was coming in (14) is interpreted differently from came; it is on a par with was getting closer to, viz. My father was getting closer to our house. This interpretation is 
expected given the meaning of PROG in (20), which requires there to be a proper part of a $P$-event. Assuming once again that events described by achievement VPs do not have proper parts, coercion takes place.

Note that the proposed analysis of the English progressive differs from what has previously been proposed in the literature. Rothstein (2004) proposes that achievement VPs are subject to a type-shifting rule when they combine with PROG because events described by such VPs do not have stages. This idea is similar in spirit to the original proposal made by Moens and Steedman (1988), who argued that PROG of an achievement VP leads to coercion because the input to PROG is a preparation and events described by an achievement VP do not have a preparation. While such proposals account for why there is coercion with the progressive, they don't extend to the Russian imperfective and Hindi SV perfective. That is, if we follow Rothstein and assume that events described by achievement VPs do not have stages, then we cannot hold the view that IPF $F_{\text {RUS }}$ makes reference to a VP-event stage; if it did, then analogous to PROG, we would expect there to be coercion (or type shifting) of some sort in, e.g. (13). In contrast, if we assume - as I have done - that events described by achievement VPs comprise atomic stages, then we can maintain the view that both $\mathrm{IPF}_{\mathrm{RUSS}}$ and PROG make reference to a VP-event stage; the difference is that the former operator requires a stage and the latter a proper-stage.

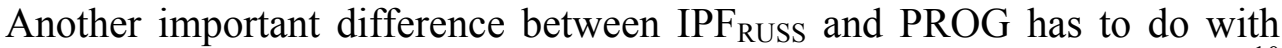
the observation that only the former is compatible with a habitual interpretation. ${ }^{10}$ To explain this difference, we can adopt Ferreira's (2005) idea that the difference between an episodic and a habitual interpretation reduces to the number (singular/plural) of the event that is quantified over: whereas an episodic interpretation involves quantification over a singular event, the habitual interpretation involves quantification over plural events. ${ }^{11}$ VP-denotations, on Ferreira's analysis, may contain singular as well as plural events. The denotations combine with one of three specialized versions of IPF: (i) $\mathrm{IPF}_{\mathrm{sg}}$, which selects sets of singular events, (ii) $\mathrm{IPF}_{\mathrm{pl}}$, which selects sets of plural events and (iii) IPF, which selects sets of (singular or plural) events. Ferreira argues that this threeway distinction "is similar to what happens in the nominal domain, where we find determiners like some, which combines with both singular and plural NPs ('some boy/some boys'), every, which combines only with singular NPs ('every boy/*every boys'), and many, which only combines with plural noun phrases ('*many boy/many boys')" (Ferreira 2005: 100).

Given Ferreira's analysis, PROG falls in the category of partitive operators

\footnotetext{
${ }^{10}$ For many speakers, the habitual is the salient interpretation in (13), but it's not possible in (14).

${ }^{11}$ The habitual involves more than quantification over plural events, e.g. expectations about the instantiation of future events. For the purposes of this paper, however, what's important is that quantification over plural events is one of the components of the habitual interpretation.
} 
There is no neutral aspect

that select for a set of singular events. Hence, it does not give rise to a habitual interpretation unless coerced. ${ }^{12} \mathrm{IPF}_{\mathrm{RUSS}}$, on the other hand, falls into the category of partitive operators that select either sets of singular or plural events (see Kagan $2007 \mathrm{a}, \mathrm{b}$ for an analysis along these lines). In particular, $\mathrm{IPF}_{\mathrm{RUSS}}$ makes reference to either (i) an event that holds in the world of evaluation and which is a stage of an event that culminates in a 'near enough' world or (ii) a series of events that hold in the world of evaluation and which are stages of events that culminate in a 'near enough' world (cf. Anand \& Hacquard 2009).

I end this section by coming back to (3) discussed at the outset. Recall that the perfective VP otkryl Ameriku ('discovered America') is used to assert that an event of discovering America was instantiated and that Columbus was happy on a different occasion. Subsequently, the imperfective VP otkryval Ameriku is used to talk about the occasion during which Columbus was happy. What's crucial is that otkryval Ameriku - which is used as an achievement in other contexts - must be understood as a non-achievement here in order to avoid a contradiction (i.e. to avoid: \#Columbus was happy not when he discovered America, but when he discovered it). The question, then, is: how does the non-achievement interpretation of otkryval Ameriku come about?

Given our implicit assumption that coercion is the resolution of a clash that comes about via function application (de Swart 1998, 2000, 2011; Bary 2009), the non-achievement interpretation of otkryval Ameriku in (3) cannot come about via coercion. Rather, it seems reasonable to assume that meanings of certain perfective forms like otkryt' Ameriku are semantically underspecified for the achievement/non-achievement distinction, i.e. the semantics of otkryt'Ameriku does not specify whether the described events have proper parts, but only that those events have culminations (i.e. the only specification is that the VP is telic). Consequently, when IPF $_{\text {RUSS }}$ combines with otkryt' Ameriku to yield otkryval Ameriku, the truth conditions are compatible with either an achievement or a nonachievement interpretation (i.e. recall that the truth-conditions of $\mathrm{IPF}_{\mathrm{RUSS}}$ are satisfied by any VP-event stage, whether it has proper parts or not). Which interpretation is actually inferred depends on specification by the context, as is the case in (3), or by the grammar (e.g. the present tense, see section 2.2).

\section{Semantic constraints imposed by the Hindi SV perfective}

The goal of this section is two-fold: (i) show that similar to the Russian imperfective, Hindi has a correlation between grammatical aspect and VP meaning and (ii) account for the difference between the two aspects.

\footnotetext{
${ }^{12}$ Moens and Steedman (1988: 18) show that the English progressive can be coerced into a habitual interpretation in e.g. Roger was running a mile last week. This week he is up to three.
} 


\subsection{A note on Hindi perfective morphology}

Hindi has traditionally been thought to have a complex aspectual system that features two perfective forms, the imperfective, the progressive and the perfect. Since only the perfectives are of direct interest to us, we focus only on these forms here. According to the traditional view, there are simple and complex forms of the perfective (henceforth: SV and CV perfective, following Singh 1998). As shown in (22), the SV perfective constitutes a suffix that is attached to the verb, while the CV perfective in (23) always takes the form: "Verb 1 Verb 2 ", where $\mathrm{Verb}_{1}$ is a bare root form describing an eventuality, while Verb $\mathrm{V}_{2}$ is a light verb that bears inflectional morphology and has lost its independent meaning; it only contributes aspectual content (e.g. Hook 1974, 1976; Butt 2003).

maayaa-ne biskuT-ko khaa-yaa

SV perfective Maya-ERG cookie-ACC eat-PFV

'Maya ate the cookie.' (Arunachalam \& Kothari 2010: 1)

maayaa-ne biskuT-ko khaa li-yaa $\quad C V$ perfective
Maya-ERG cookie-ACC eat take-PFV
'Maya ate the cookie.' (Arunachalam \& Kothari 2010: 1)

The semantic criteria typically used to argue that the verbal forms in (22) and (23) are perfective comes from the observation that the inference one draws from these sentences is that the described event was completed (recall the discussion of (22) at the outset of this paper). The difference between (22) and (23) is not clear, however, at least without further context. According to Kothari (p.c.), the light verb "may sometimes be associated with other semantic dimensions such as suddenness, volitionality, benefaction, etc., which can lend an extra shade of meaning to the main verb..." To the best of my knowledge, however, these "other semantic dimensions" have-for the most part-been ignored, at least in the literature on formal semantic and pragmatics.

In the next section, we consider examples such as (22)-(23) with surrounding context. Such data reveals that there is a clear difference between the SV and CV forms. Much of this discussion builds on the seminal work by Mona Singh (1991, 1998), where it is argued that in Hindi "the perfective of simple verbs is used for arbitrary endpoints, and the so-called compound verbs (CV) for natural endpoints" (Singh 1998: 173).

\subsection{Culmination entailment with the Hindi SV perfective}

As first noticed by Singh $(1991,1998)$, and later discussed by Arunachalam \& Kothari (2010: 1), (22) and (23) above differ in that the use of the CV perfective leads to a culmination entailment, whereas the use of the SV perfective leads to a cancelable culmination inference. This is shown in (24) and (25) below. 
There is no neutral aspect

maayaa-ne biskuT-ko khaa-yaa (par use puuraa nahiin khaa-yaa) Maya-ERG cookie-ACC eat-yaa but it-ACC finish not eat-yaa 'Maya was eating the cookie (but did not finish it).'

maayaa-ne biskuT-ko khaa li-yaa (\#par use puuraa nahiin khaa-yaa) Maya-ERG cookie-ACC eat-yaa but it-ACC finish not eat-yaa 'Maya ate the cookie (\#but did not finish it).'

Singh (1998) provides many more examples where the SV perfective leads to a cancelable implicature. Notice, however, that the VP in (24) is not an achievement. When a VP is an achievement, the SV perfective leads to a culmination entailment just like the Russian imperfective, viz. (6) discussed at the outset. Singh concludes that for "...the class of instantaneous predicates...[b]oth SVs and CVs in the perfective aspect indicate that the described action was completed" (ibid: 183). This suggests that the proposed semantic constraints imposed by the Russian imperfective are also imposed by the SV perfective. That is, operators corresponding to these aspects denote functions that return VP-event stages; they could describe an event's culmination, but this depends, in part, on whether the input is an achievement. ${ }^{13}$

What differentiates the Russian imperfective from the Hindi SV perfective has to do with particular restrictions on the way an event develops in the actual world. This restriction is illustrated by the following contrast:
Ja e-l
tort, i sejčas prodolžaju ego est'.
I eat.IPF-PST.1S cake and now continue it eat.INF
'I was eating cake and now I am still eating it.'
\#maayaa-ne biskuT-ko khaa-yaa aur use ab tak khaa rahii hai Maya-ERG cookie-ACC eat-PFV and it still eat PROG be.PRS Intended: 'Maya was eating the cookie, and is still eating it.'

If we adopt an analysis for the Hindi SV perfective that is on a par to the Russian imperfective, the infelicity (27) would be unexpected. That is, we would expect (27) to be compatible with a situation in which there was a partial cookie-eating in the past that continued to develop until the time of utterance. This is a prototypical situation that is used to characterize the progressive interpretation and one that is compatible with the Russian imperfective in (26).

In order to explain this contrast, let us consider Koenig \& Muansuwan's (2000) analysis of the Thai perfective $k^{h} \hat{u} n$, which shows a contrast similar to

\footnotetext{
${ }^{13}$ Singh (1998) observes that SV perfective of non-achievements lead to a culmination entailment when the object DP has a mass interpretation. Integrating Singh's analysis of this phenomenon with what is proposed here would take us too far afield, but is possible; it would involve incorporating the interaction between telicity and quantification.
} 
Hindi:

(28) Surii téç klǒon sǒon bòt $\mathbf{k}^{\mathbf{h}} \mathbf{u} \mathbf{u}$ tèc jạ mâj sèd

Surii compose poem two CL ascend but still not finish

'Surii composed two poems, but has not finished them yet.'

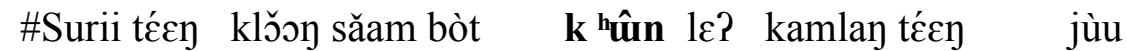

Surii write poem three CLASS ascend and PROG compose CONT

'Surii composed three poems and is still composing them.'

Koenig and Muansuwan propose that accomplishment VPs like those in (28)-(29) are inherently modal. Moreover, building on Krifka's (1989) notion of an event's terminal point relative to an event-description $\phi$, they propose that these VPs combine with a maximality operator defined in (30) below. It denotes a function that maps an eventuality description onto another eventuality description.

(30) The referent of a discourse marker $e$ satisfies the predicative condition $\operatorname{Max}(e, \phi)$ iff $e$ is the largest eventuality which satisfies $\phi$, i.e. if there is no eventuality $e^{\prime \prime}$ such that $e \sqsubset e^{\prime \prime}$ which satisfies the description $\phi$.

Applying (30) to (28)-(29) above amounts to saying that the event $e$ that warrants the assertion must be the maximal subpart of the possible continuations $e^{\prime}$ that would fit the event description of Surii composing poems. This requirement is not violated by the denial in (28) because it merely asserts that there is an event $e$ that is a subpart of an event $e^{\prime}$ that fits the description of Surii composing poems. In (29), however, the requirement is violated because the denial not only states that $e$ is a subpart of $e^{\prime}$, but that there is also an event $e$ " ongoing at the speech time that both properly includes $e$ and fits the description of Surii composing poems.

An analysis of this kind was also proposed by Filip $(2000,2008)$ to account for the perfective in Slavic languages. She proposed (roughly) that the perfective denotes a maximalization operator from a set of events to a set of maximal event stages. This idea can be easily implemented into the analysis proposed in the previous section, which already incorporates Landman's stage-of relation. To that end, I propose that Hindi has an operator ${ }^{\mathrm{SV}} \mathrm{PFV}$, which corresponds to the SV perfective. This operator encodes the constraints of IPF $_{\text {RUSS }}$ and, in addition, includes the requirement in $0 \mathrm{v}$ below, which I shall call the maximal stage

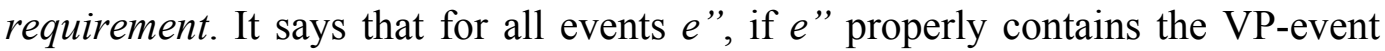
part denoted by $e^{\prime}$ and is at least a sub-part of the VP-event denoted by $e$, then $e$ " does not satisfy the description denoted by the VP in $w^{*}$. In other words, $0 \mathrm{v}$ is satisfied in one of two ways: an event part denoted by $e^{\prime}$ culminates or ceases to develop in $w^{*}$. In both cases, there could not be an event that is more developed than $e^{\prime}$ in $w^{*}$ that has the property $P$ (though there would be a more developed version of $e^{\prime}$ in some possible world $w$ ). 
There is no neutral aspect

\begin{tabular}{|l|c|c|c|}
\hline & Partitive operator & Proper VP-event stage? & Maximal stage? \\
\hline (a) & ${ }^{\text {SV }}$ PFV & No & Yes \\
\hline (b) & ${ }^{\text {RUS }}$ IPF & No & No \\
\hline (c) & PROG & Yes & No \\
\hline (d) & $? ? ?$ & Yes & Yes \\
\hline
\end{tabular}

Figure 1 Typology of partitive operators

a. $\quad{ }^{\mathrm{SV}} \mathrm{PFV} \rightsquigarrow \lambda P \lambda e^{\prime} \exists e \exists w\left[\operatorname{MAXSTAGE}\left(e^{\prime}, e, w^{*}, w, P\right)\right]$

b. $\llbracket \operatorname{MAXSTAGE}\left(e^{\prime}, e, w^{*}, w, P\right) \rrbracket^{2 n,} \mathrm{~g}=1$ iff (i)-(iv) holds:

(i) the history of $\mathrm{g}(w)$ is the same as the history of $\mathrm{g}\left(w^{*}\right)$

up to and including $\tau\left(\mathrm{g}\left(e^{\prime}\right)\right)$

(ii) $\mathrm{g}(w)$ is a reasonable option for $\mathrm{g}\left(e^{\prime}\right)$ in $\mathrm{g}\left(w^{*}\right)$

(iii) $\llbracket P \rrbracket^{20, \mathrm{~g}}(e, w)=1$

(iv) $\mathrm{g}\left(e^{\prime}\right) \sqsubseteq \mathrm{g}(\mathrm{e})$

(v) $\forall e^{\prime \prime}\left[\left(\mathrm{g}\left(e^{\prime}\right) \sqsubset e^{\prime \prime} \wedge e^{\prime \prime} \sqsubseteq \mathrm{g}(e)\right) \rightarrow \llbracket P \rrbracket^{\mathrm{M}, \mathrm{g}}\left(e^{\prime \prime}, w^{*}\right)=0\right]$

\section{Conclusion}

In sum, this paper has provided an analysis of three aspectual operators: ${ }^{\text {RUSS }}{ }^{2}$ PF, PROG and ${ }^{S V}$ PFV which all denote functions that return VP-event stages, i.e. these operators are partitive. What makes these three operators distinct is whether they require proper VP-event stages and whether they impose a maximal stage requirement in $0 \mathrm{v}$ above. This leads to the typology in Fig. 1 above. ${ }^{14,15}$ Assuming that PROG is a kind of an imperfective operator (Comrie 1976), we can summarize the typology as follows: both perfective and imperfective operators could describe an event's culmination; this depends on whether the operator requires proper stages in the extension of the VP that it combines with. In other words, the combination of a partitive operator with a VP could (but need not)

\footnotetext{
${ }^{14}$ If we include the 'number parameter' (discussed in section 2)-which is linked to whether an operator is compatible with the habitual interpretation - many more possibilities are predicted.

${ }^{15}$ The typological gap in (d) characterizes an operator that requires a proper VP-event stage (and hence coercion with achievement VPs) and also encodes the maximal stage requirement. That is, we predict the possibility of an operator that would combine with an achievement VP like arrive and yield something like stop arriving. At this point, I am not aware of such an operator.
} 
result in a telic predicate, but this is independent of (im)perfectivity. What differentiates between imperfective and perfective operators is whether they encode the maximal stage requirement:

(32) Hypothesis about (im)perfective operators

a. An operator is perfective if it requires a maximal stage of an event in the extension of the VP that it combines with.

b. An operator is imperfective if it requires a stage of an event in the extension of the VP that it combines with, but it need not be maximal.

Several questions arise. One concerns how (32)a relates to atelic SV perfective forms in Hindi, viz. (33) below, or perfective CV forms in Hindi, viz. (34), which always lead to a culmination entailment.

$$
\begin{aligned}
& \text { maya-ne saikil chalaa-yii } \\
& \text { Maya-ERG bicycle ride-PFV } \\
& \text { 'Maya rode the bicycle.' } \\
& \text { maayaa-ne biskuT-ko khaa li-yaa } \\
& \text { Maya-ERG cookie-ACC eat take-PFV } \\
& \text { 'Maya ate up the cookie.' }
\end{aligned}
$$

An atelic form like chalaa-yii ('ride the bicycle') in (33) trivially satisfies the maximal stage requirement because it is cumulative: adding a bicycle-riding event to a bicycle-riding event yields a bicycle-riding event. Therefore, there could not be a more developed version of the bicycle-riding event that warrants the assertion in (33). In other words, the bicycle-riding event that warrants the assertion in (33) is trivially maximal.

Similarly, CV perfective forms like khaa li-yaa ('ate') in (34) trivially satisfy the maximal stage requirement if we assume that the $\mathrm{CV}$ perfective denotes a non-partitive operator that returns a set of event wholes (not parts), with culminations. And by returning a set of culminated events, the $\mathrm{CV}$ perfective denies any further development relative to an event description.

In sum, both partitive and non-partitive perfective operators (e.g. the SV and the $\mathrm{CV}$ perfective in Hindi) satisfy the maximal stage requirement, but only the former (e.g. the SV perfective) can satisfy this requirement by describing an event that ceased to develop without culminating in the actual world.

Another question that arises for the analysis concerns (32)b, and in particular, whether all imperfective operators do, in fact, require a stage of an event in the extension of the VP that they combines with. As is well known, stative VPs in many of the world's languages (for example in Romance) have imperfective morphology. In turn, we know from Landman $(1992,2007)$ and subsequent work that states do not have stages. This leads us to two possible hypotheses. The first hypothesis is that stative VPs have the characteristics of imperfective forms but 
There is no neutral aspect

these characteristics are not derived via an imperfective operator. The second hypothesis would be to say that an operator is imperfective if it requires a part (rather than a stage) of an event in the extension of the VP that it combines with. The idea would then be that all imperfective operators require VP-event parts, though a given imperfective operator may differ in whether these parts must necessarily be stages (as in the case of PROG) or not (as in the case of e.g. IPF in Romance). I leave this issue open for further research.

The final question that I'd like to address concerns the typology in Fig. 1 above: What implications (if any) do the proposed parameters have for the internal system of languages? For example, we could ask the following question about a partitive aspectual operator $Q$ and non-partitive aspectual operator $R$ in a given language $L$ : Is the absence of a constraint on proper stages in $R$ mirrored in the presence of such a constraint in $Q$ ? This question relates to a more general question, namely whether the typology in Fig. 1 is an attempt to develop an ordered, potentially infinite +/- parameter setting or whether we should expect limitations on variation, and interaction between the parameters.

The position taken here is that in a given language, we should not expect limitations on variation between the parameters - at least if we consider the parameters proposed in Fig. 1. The aspectual system of Hindi-which morphologically distinguishes between the SV perfective, the progressive and the imperfective - shows us that a language can have as many as three forms that denote partitive operators. While the progressive and the imperfective in Hindi have not been discussed, the former does not appear to differ from English. If that's right, then (minimally) two of the partitive operators in Hindi differ in the two parameters proposed in this paper.

Despite the apparently unconstrained nature of the typology, it seems reasonable to assume that there is at least one aspectual parameter which interacts with the ones proposed here in interesting ways: the relation encoded by an aspectual operator between the described event and the so-called reference time. It has often been observed that such a relation models our ability to understand two or more events as standing in a narrative sequence and this, in turn, is dependent on our understanding that the events in question culminated (Kamp 1979, Dowty 1986). If this is correct, then we should see limitations on variation between aspectual parameters. Moreover, we should see interesting consequences in how particular parameters interact within a given language. An important research question worthy of pursuit is to see whether it is the language-internal interaction between aspectual parameters that leads to the aforementioned culmination implicature with the Russian imperfective and the Hindi SV perfective when they combine with non-achievements. The analysis presented here has said nothing about how these implicatures are generated and remains one of the outstanding questions for analyses of aspect and temporality more generally. 


\section{References}

Academy Grammar. 1960. Akademija nauk SSSR. Russkaja grammatika, Tom II. Moscow: Nauka.

Altshuler, Daniel. 2010. Temporal interpretation in narrative discourse and event internal reference. Rutgers University: Ph.D. dissertation.

Altshuler, Daniel. 2012. Aspectual meaning meets discourse coherence: A look at the Russian imperfective. Journal of Semantics 29. 39-108.

Anand, Pranav and Valentine Hacquard. 2009. The role of the imperfect in Romance counterfactuals. In Martin Prinzhorn, Viola Schmitt and Sarah Zobel (eds.), Proceedings of Sinn und Bedeutung 14.

Arunachalam, Sudha, \& Kothari, Anubha. 2010. Telicity and event culmination in Hindi perfectives. In Pier Bertinetto, Anna Korhonen, Alessandro Lenci, Alissa Melinger, Sabine Schulte im Walde \& Aline Villavicencio (eds.), Proceedings of Verb 2010, Interdisciplinary Workshop on Verbs: The Identification and Representation of Verb Features, 16-19.

Bar-El, Leora, Henry Davis, \& Lisa Matthewson. 2005. On non-culminating accomplishments. In Leah Bateman \& Cherlon Ussery (eds.), Proceedings of the 35th Annual Meeting of the North East Linguistics Society, 87-102.

Bary, Corien. 2009. Aspect in Ancient Greek. A semantic analysis of the aorist and imperfective. Radboud University, Nijmegen: Ph.D. dissertation.

Bittner, Maria. 2007. Aspectual universals of temporal anaphora. In S. Rothstein, (ed.), Theoretical and Crosslinguistic Approaches to the Semantics of Aspect, 349-385. Amsterdam: John Benjamins.

Boneh, Nora \& Edit Doron (2008) Modal and temporal aspects of habituality. In Malka Rappaport-Hovav, Edit Doron \& Ivy Sichel (eds.), Syntax, Lexical Semantics, and Event Structure, 338-363. Oxford: Oxford University Press.

Bonomi, Andrea. 1997. The Progressive and the Structure of Events. Journal of Semantics 14. 173-205.

Borik, Olga. 2006. Aspect and Reference Time. Oxford: Oxford University Press.

Butt, Miriam. 2003. The light verb jungle. In Conor Quinn, Claire Bowern and Gülsat Aygen (eds.), Harvard Working Papers in Linguistics, Volume 9: Papers from the GSAS/Dudley House Workshop on Light Verbs, 1-49. Cambridge: Harvard University.

Comrie, Bernard. 1976. Aspect. Cambridge University Press.

Condoravdi, Cleo. 2009. Measurement and Intensionality in the Semantics of the Progressive. Handout of talks presented at Yale University, April 2009, Kyoto University, September 2009, University of Texas at Austin, November 2009. http://www2.parc.com/isl/members/condorav 
There is no neutral aspect

Csirmaz, Aniko. 2004. Perfective and imperfective in Hungarian: (Invisible) differences. In Sylvia Blaho, Luis Vicente \& Mark de Vos (eds.), Proceedings of Console XII, 1-16. University of Leiden.

Dahl, Eystein. 2010. Time, Tense and Aspect in Early Vedic Grammar: Exploring Inflectional Semantics in the Rigveda. Brill Academic Publishers.

Dell, François. 1987. An aspectual distinction in Tagalog. Oceanic Linguistics 2223.175-207.

Deo, Aswini. 2006. Tense and aspect in Indo-Aryan languages: Variation and diachrony. Stanford University: Ph.D. dissertation.

Dowty, David. 1979. Word meaning and Montague Grammar. Dordrecht: Reidel.

Dowty, David. 1986. The effects of aspectual class on the temporal structure of discourse: semantics or pragmatics? Linguistics and Philosophy 9. 37-61.

Ferreira, Marcel. 2005. Event Quantification and Plurality. Massachusetts Institute of Technology: Ph.D. dissertation.

Filip, Hana. 1999. Aspect, Eventuality Types and Noun Phrase Semantics. New York: Routledge.

Filip, Hana. 2000. The quantization puzzle. In Carol Tenny \& James Pustejovsky (eds.), Events As Grammatical Objects, From the Combined Perspectives of Lexical Semantics, Logical Semantics and Syntax, 39-91. Stanford: CSLI Press.

Filip, Hana. 2008. Events and Maximalization. In Susan Rothstein (ed.), Theoretical and Crosslinguistic Approaches to the Semantics of Aspect, 217-56. Amsterdam: John Benjamins.

Giorgi, Alexandra \& Fabio Pianesi. 2001. Ways of Terminating. In Carlo Cecchetto, Gennaro Chierchia, and Maria Teresa Guasti (eds.), 211-277. Semantic Interfaces: Reference, Anaphora and Aspect. Stanford. CSLI Press.

Grønn, Atle. 2003. The Semantics and Pragmatics of the Russian Factual Imperfective. University of Oslo: Ph.D. dissertation.

Hook, Peter. 1974. The Compound Verb in Hindi. The University of Michigan Center for South and Southeast Asian Studies.

Hook, Peter. 1976. The Hindi compound verb: What it is and what it does. In Kripa Shanker Singh (ed.), Readings in Hindi-Urdu Linguistics, 129-46. Delhi: National Publishing House.

Iatridou, Sabine, Elena Anagnostopoulou and Roumyana Izvorski. 2001. Observations about the form and meaning of the perfect. In Michael Kenstowicz (ed.), Ken Hale. A Life in Language, 153-204. Cambridge, MA: MIT Press

Ikegami, Yoshihiko. 1985. 'Activity'-'Accomplishment'-'Achievement'-A language that can't say 'I burned it but it did not burn' and one that can. In Adam Makkai and Alan K. Melbeds (eds.), Linguistics and Philosophy: 
Essays in Honor of Rulon S. Wells, 265-304. Amsterdam: John Benjamins.

Kagan, Olga. 2007a. On the Semantics of Verbs of Motion in Russian. In Yehuda Falk (ed.), Proceedings of IATL 23, 1-15.

Kagan, Olga. 2007b. Russian aspect as number in the verbal domain. Presented at the Workshop on Nominal and Verbal Plurality, November 9-10, CNRS Pouchet.

Kamp, Hans. 1979. Events, instants and temporal reference. In Rainer Bäuerle, Urs Egli \& Arnim von Stechow (eds.), Semantics from Different Points of View, 376-471. Berlin: De Gruyter.

Kamp, Hans \& Christian Rohrer. 1983. Tense in texts. In Rainer Bäuerle, Urs Egli \& Arnim von Stechow (eds.), Meaning, use and interpretation of language, 250-69. Berlin: Mouton de Gruyter.

Kamp, Hans \& Uwe Reyle. 1993. From Discourse to Logic: Introduction to Modeltheoretic Semantics of Natural Language, Formal Logic and Discourse Representation Theory. Dordrecht: Kluwer.

Kamp, Hans, van Genabith, Josef \& Uwe Reyle. 2011. Discourse Representation Theory. In Dov Gabbay \& Franz Guenthner (eds.), 125-394. Handbook of Philosophical Logic. Dordrecht: Kluwer.

Kiyota, Masaru. 2008. Situation aspect and viewpoint aspect: From Salish to Japanese. University of British Columbia: Ph.D. Thesis.

Klein, Wolfgang. 1994. Time in Language. London: Routledge.

Koenig \& Muansuwan. 2000. How to end without finishing: Thai semi-perfective markings. Journal of Semantics 17: 147-184.

Koenig, Jean-Pierre \& Liangcheng Chief. 2008. Scalarity and state-Changes in Mandarin, Hindi, Tamil, and Thai. In Olivier Bonami and Patricia Cabredo Hofherr (eds.), Empirical Issues in Syntax and Semantics 7, 241262.

Kratzer, Angelika. 1998. More structural analogies between pronouns and tenses. Proceedings of Semantics and Linguistic Theory 8, 92-110. Cornell University: CLC Publications.

Krifka, Manfred. 1989. Nominal reference, temporal constitution, and quantification in event semantics. In Renate Bartsch, Johan van Benthem, \& Peter van Emde Boas (eds), Semantics and Contextual Expressions, 75115. Foris, Dordrecht.

Landman, Fred. 1992. The progressive. Natural Language Semantics 1: 1-32.

Landman, Fred. 2007. 1066: On the differences between the tense-perspective aspect systems of English and Dutch. In Susan Rothstein (ed.), Theoretical and Crosslinguistic Approaches to the Semantics of Aspect, 107-67. Amsterdam: Johns Benjamins. 
There is no neutral aspect

Leinonen, Marja. 1982. Russian aspect, 'temporal'naja lokalizacija', andefiniteness/indefiniteness. University of Helsinki: Ph.D. thesis.

Maslov, Jurij. 1984. Očerki po aspetologii. Leningrad: Izatel'stvo Leningtadskogo universiteta.

Meulen, Alice ter. 1995. Representing Time in Natural Languages. MIT Press, Cambridge, MA.

Moens, Marc \& Mark Steedman. 1988. Temporal ontology and temporal reference. Computational Linguistics 14. 15-28.

Pancheva, Roumyana. 2003. The aspectual makeup of perfect participles and the interpretations of the perfect. In Artemis Alexiadou, Monika Rathert \& Arnim von Stechow (eds.), Perfect Explorations. The Hague: Mouton de Gruyter.

Parsons, Terence. 1990. Events in the Semantics of English. A Study in Subatomic Semantics. Cambridge: MIT Press.

Paslawska, Alla \& Arnim von Stechow. 2003. Perfect readings in Russian. In Artemis Alexiadou, Monika Rathert \& Arnim von Stechow (eds.), Perfect Explorations, Interface Explorations, 307-62. Berlin: Mouton de Gruyter.

Pederson, Eric. 2007. Event realization in Tamil. In Penelope Brown and Melissa Bowerman (eds.), Cross-linguistic Perspectives on Argument Structure: Implications for Learnability, 331-355. New York: Lawrence Erlbaum.

Portner, Paul. 1998. The progressive in modal semantics. Language 74. 760-787.

Raja, Nasim. 2003. Aspectual complex predicates in Punjabi. In Raja Singh (ed.), The Yearbook of South Asian Languages and Linguistics, 99-129. Berlin: Walter de Gruyter.

Rassudova, Olga. 1968. Upotreblenie vidov glagola. Moscow: Mežduharodnyj seminar prepodavatelej russkogo jazyka zarubežnykh stran.

Rassudova, Olga. 1984. Aspectual Usage in Modern Russian. Moscow: Russkij jazyk.

Rothstein, Susan. 2004. Structuring Events. Blackwell Publishing.

Schilder, Frank. 1995. Aspect and discourse structure: Is a neutral viewpoint required? In Proceedings of the $33^{\text {rd }}$ Annual Meeting of ACL, 326-328. Cambridge, MA: MIT.

Singh, Mona. 1991. The perfective paradox: Or, how to eat your cake and have it too. In Laurel Sutton, Christopher Johnson \& Ruth Shields (eds.), Proceedings of the Seventeenth Annual Meeting of the Berkeley Linguistics Society, 469-79. Berkeley: University of California, Berkeley.

Singh, Mona. 1998. On the semantics of the perfective aspect. Natural Language Semantics 6. 171-199.

Smith, Carlota. 1994. The Parameter of Aspect. Dordrecht: Kluwer.

von Stechow, Arnim. 2009. Tense in compositional semantics. In Wolfgang Klein \& Ping Li (ed.), The Expression of Time, 129-166. Mouton De Gruyter. 
de Swart, Henriette. 1998. Aspect shift and coercion. Natural Language and Linguistic Theory 16. 347-85.

de Swart, Henriette. 2000. Tense, aspect and coercion in a cross-linguistic perspective. Proceedings of the Berkeley Conference on Formal Grammar. http:www.csli-publications.stanford.edu

de Swart, Henriette. 2011. Mismatches and coercion. Semantics: An International Handbook of Natural Language Meaning, 574-597. Berlin: De Gruyter.

Tatevosov Tatevosov, Sergei. 2008. Subevental structure and non-culmination. In Olivier Bonami, Patricia Cabredo Hofherr (eds.), Empirical Issues in Syntax and Semantics 7, 393-422.

Teng, Shou-hsin. 1972. A semantic study of the transitivity relations. University of California, Berkeley: Ph.D. dissertation.

Townsend, Charles. 1975. Russian Word Formation. Slavica Pub.

Travis, Lisa. 2000. Event structure in syntax. In Carol Tenny and James Pustejovsky (eds.), Events as Grammatical Objects: The Converging Perspectives of Lexical Semantics and Syntax, 145-185. Stanford: CSLI Publications.

Vinogradov, Viktor. 1972. Russkij jazyk. Moscow: Vysšaja škola.

Zucchi, Sandro. 1999. Incomplete events, intensionality, and imperfective aspect. Natural Language Semantics 7. 179-215.

Daniel Altshuler

Department of Linguistics, Heinrich-Heine-Universität Düsseldorf

Universitätsstr. 1

40225 Düsseldorf, Germany

daltshul@gmail.com 